\title{
Olivier Dollfus, una pasión por los Andes
}

\section{Evelyne Mesclier, Henri Godard y Jean-Paul Deler}

\section{(2) OpenEdition}

\section{Journals}

Edición electrónica

URL: http://journals.openedition.org/bifea/5565

DOI: 10.4000/bifea.5565

ISSN: 2076-5827

\section{Editor}

Institut Français d'Études Andines

\section{Edición impresa}

Fecha de publicación: 1 mayo 2005

Paginación: 1-4

ISSN: 0303-7495

\section{Referencia electrónica}

Evelyne Mesclier, Henri Godard y Jean-Paul Deler, « Olivier Dollfus, una pasión por los Andes », Bulletin de l'Institut français d'études andines [En línea], 34 (1) | 2005, Publicado el 08 abril 2005, consultado el 10 diciembre 2020. URL : http://journals.openedition.org/bifea/5565 ; DOI : https://doi.org/10.4000/ bifea. 5565

Les contenus du Bulletin de l'Institut français d'études andines sont mis à disposition selon les termes de la licence Creative Commons Attribution - Pas d'Utilisation Commerciale - Pas de Modification 4.0 International. 


\title{
Olivier Dollfus, una pasión por los Andes
}

\author{
Évelyne Mesclier ${ }^{*}$ \\ Henri Godard** \\ Jean-Paul Deler ${ }^{* * *}$
}

En la sabiduría aymara, el pasado está por delante de nosotros y podemos verlo alejarse, mientras que el futuro está detrás nuestro, invisible e irreversible; Olivier Dollfus apreciaba esta metáfora del hilo de la vida y del curso de la historia. En el 2004, marcado por las secuelas físicas de un grave accidente de salud pero mentalmente alerta, realizó su más caro sueño desde hacía varios años: regresar al Perú, que iba a ser su último gran viaje. En 1957, el joven de 26 años que no hablaba castellano, aterrizó en Lima por vez primera, luego de un largo sobrevuelo sobre América del Sur con un magnífico clima, atravesando la Amazonía y los Andes — de los que se enamoró inmediatamente- hasta el desierto costero del Pacífico. Entre estas dos fechas se desplegó su pasión por el Perú, que habrá sido para él lo que Brasil fue para Claude Lévi-Strauss, quien en una entrevista reciente declaró: «Brasil representa la experiencia más importante de mi vida».

\section{SECUENCIAS DE UN PASADO}

En el 2004, luego de un cálido reencuentro, alrededor de una mesa redonda se rindió un homenaje muy sencillo, en el Instituto Francés de Estudios Andinos, a este director que lo marcó con su huella. Con un pisco sour y unos bocaditos, todos sin distinción le testimoniaron con emoción su reconocimiento y respeto a Olivier Dollfus, personalidad conocida por todos incluso hasta por los más jóvenes.

\footnotetext{
* Institut de Recherche pour le Développement (IRD). Correo electrónico: evelyne.mesclier@wanadoo.fr

** Institut Français d'Études Andines (Iféa). Correo electrónico: hgodard@ifea.org.pe

${ }^{* * *}$ Centre National de la Recherche Scientifique (CNRS). Correo electrónico: deler@ades.cnrs.fr
} 


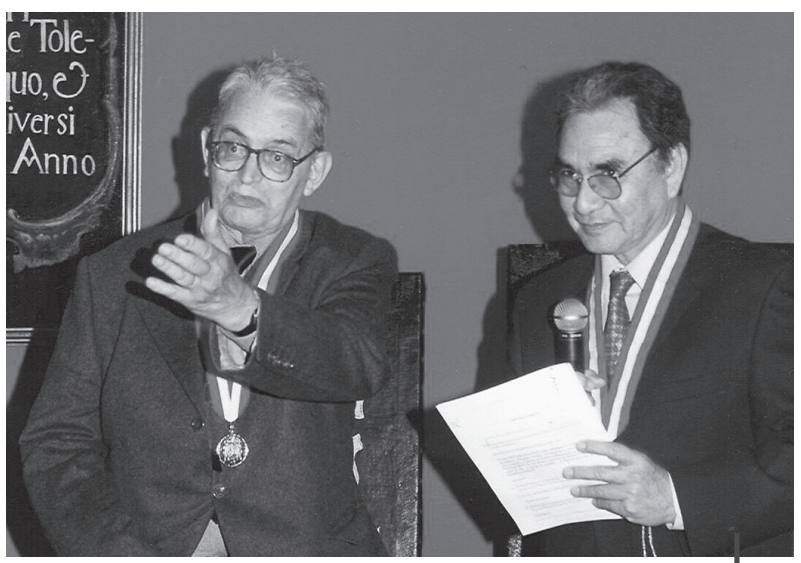

Figura 1 - Olivier Dollfus en la ceremonia de su nombramiento como Doctor Honoris causa en la UNMSM, mayo 2004
El doctorado Honoris causa que le confirió la Universidad Nacional Mayor de San Marcos, más que cualquier otra ceremonia, lo emocionó de manera indeleble. En el recinto de la Casona, nos mostró con orgullo el aula donde enseñaba, casi medio siglo antes. Sus queridos amigos peruanos, que lo recibieron con tanta estima y amistad durante este último viaje andino, tanto como los magníficos paisajes del Perú, iluminaron los meses postreros de Olivier.

Pero este hombre no se eternizaba en el confort de los locales académicos. Durante esta breve estadía, sacando fuerzas de la energía vital que lo caracterizaba, Olivier no dejó de atraer nuestra atención una y otra vez sobre las maravillas de su querido Perú. Maravillas de los lugares y de los paisajes que estábamos redescubriendo juntos — la paz de las iglesias de Lima, el luminoso desierto de Ica, los brumosos acantilados de Paracas, el valle del Supe magnificado por Caral—, maravillas de aquellos que conservaba vivos en su memoria, como las cimas nevadas de la Cordillera Blanca, que tanto hubiese querido poder alcanzar, tesoros escondidos de los peruanos, también.

«iMagnífico!» fue la expresión recurrente de una estadía intensamente vivida. En todos los caminos así como en Lima frente a la neblina que devela y disimula, frente a San Agustín o en la Alameda de los Descalzos, nos contó infatigablemente sus anécdotas, como para transmitir mejor, una vez más, una geografía vivida mucho tiempo. La de los barrios, la de las dinámicas aceleradas de una aglomeración a la vez única y emblemática de la historia del mundo y de la mundialidad. Y, en los cuatro rincones de la cordillera y de la selva amazónica, la del incierto combate por el espacio, del inevitable compromiso, entre actores de la globalización - o del antimundo-y de los habitantes a quienes tenía costumbre de interrogar incansablemente. Esta memoria llegaba al detalle -las aventuras del fantasma que reinaba en el local del Instituto Francés de Estudios Andinos, en ese entonces instalado en el Edificio Rímac, al borde del centro histórico- y por el relato de viajes salpicados de incidentes graciosos. No olvidaba a los seres, a través de los retratos de amigos o de relaciones bosquejadas con humor y fineza. Esta memoria transmitía hasta qué punto la construcción de un conocimiento científico pasa también por la comprensión inmediata, corporal, del espacio, de sus accidentes, de su belleza, de las distancias y de las interdependencias.

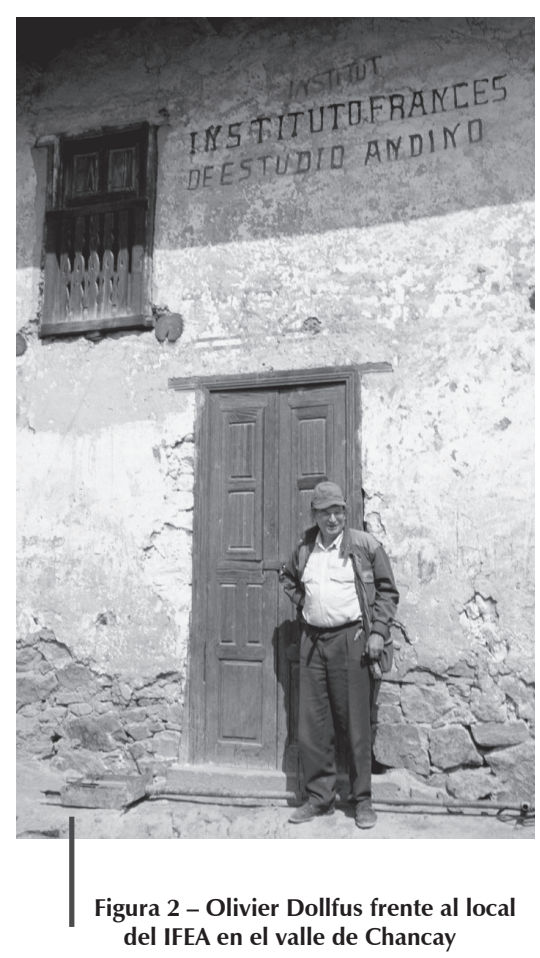




\section{TIEMPO GANADO CONSAGRADO A LA ACCIÓN, A LOS OTROS, AL MUNDO}

Símbolo de una determinación que no lo abandonaba, Olivier seguía consagrando mucho más tiempo a la lectura de los diarios, al comentario de la actualidad nacional e internacional, a la asistencia a conferencias y debates — entre algunas compras destinadas a sus nietas - así como a la degustación de una cocina que apreciaba sin embargo en su justo valor. Porque no temía declarar que quien come rápido trabaja igualmente rápido. iEn el 2004 nuevamente nos dio el ejemplo! Estábamos lejos de imaginar que su impulsión vital iba a apagarse tan rápidamente: desde que retornó a París no cesó de hablarnos de próximos viajes, a Bulgaria, a Ecuador... ¿Cómo no admirar a un hombre que, privado del movimiento de la mitad de su cuerpo, no cesaba de recorrer las calles de París, las exposiciones — una de las últimas que contempló, dedicada a la pintura colonial de Cusco-y de visitar a sus amigos en Francia y en el extranjero? ¿Cómo imaginar que ya no iríamos nunca más a visitarlo en su casa de la rue Royale en París, inquietos por sus consejos, por sus puntos de vista, por su estímulo, o simplemente felices de compartir con él las noticias de la vida y del Mundo? Hasta su último aliento, Olivier se habrá esforzado por reunir alrededor suyo a todos aquellos a quienes los Andes un

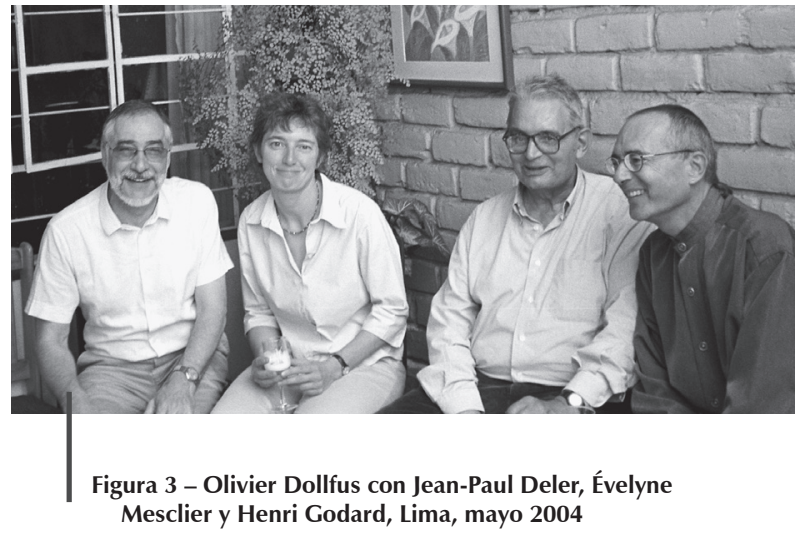
día los cambiaron por siempre.

Con esta inagotable energía, que sin duda todos envidiábamos, Olivier contribuyó de manera excepcionalmente importante al desarrollo de la investigación francesa y de la investigación en general en los Andes, particularmente en el Perú. Con el paso de las décadas

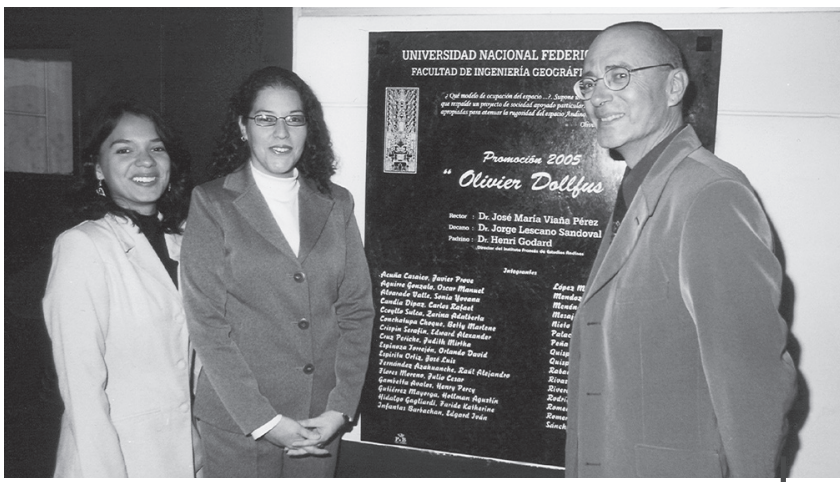

Olivier, que apreciaba a cada uno según sus compromisos, no cesó de traducir, en medios de estudio y en líneas de acción, el interés que les tenía a los países andinos. Lo hizo sin traicionar a Francia a quien había representado, pero con el afán de dar sin quitar y de reforzar la investigación académica andina. El análisis de la situación del Perú, sumido en la violencia y la crisis a fines de los años 1980, le había inspirado el concepto de «caos limitado» que desarrolló en 1991 en L'Espace géographique para, a partir del caso peruano,

Figura 4 - Ceremonia académica de entrega de título profesional a la promoción «Olivier Dollfus», Facultad de Ingienería extenderlo a otras situaciones Geográfica y Ambiental de la Universidad Nacional Federico Villareal, junio 2005 de países del tercer mundo. Este concepto, innovador en geografía, 
que testimonia sobre los desórdenes del mundo, no le impidió a Olivier, gran optimista, conservar la esperanza de un cambio de política y de una salida de la crisis, en el Perú en particular.

\section{PALABRA INTACTA}

«Juntos hemos amado a los Andes y a los vastos horizontes peruanos» escribió en el prefacio de su tesis en 1965. Después de cuatro décadas y de varias generaciones de investigadores y de amigos, su palabra permanece intacta. Él nos ha hecho descubrir y comprender a los Andes, pero de hoy en adelante, ya no los veremos de la misma manera, nos faltará su estimulante compañía. Desde este 1 ro de febrero de 2005 — demostrativo que le gustaba poner en sus cartas manuscritas- Olivier Dollfus descansa al pie del Macizo del Sancy, en Tauves, en medio de la serenidad de los Montes de Auvernia, otras montañas que también amaba. 